\title{
Will High Dose Rate Interstitial Brachytherapy Be a Surrogate to Surgery in Early Mobile Squamous Cell Carcinoma of Tongue-An Indian Experience
} \author{
Vivekanandam Singhavajhala ${ }^{1}$ \\ ${ }^{1}$ Department of Radiotherapy, JIPMER, Puducherry, India \\ ${ }^{2}$ Department of Medical Physics, JIPMER, Puducherry, India \\ Email: dr patchu2003@yahoo.co.in
}

Parthasarathy Vedasoundaram¹, K. S. Reddy', Gangotri Selvarajan1, Saravanan Kandasamy2, Mourougan Sinnathambi'2, Muzamil Asif',

Received 24 May 2014; revised 23 June 2014; accepted 22 July 2014

Copyright (C) 2014 by authors and Scientific Research Publishing Inc. This work is licensed under the Creative Commons Attribution International License (CC BY). http://creativecommons.org/licenses/by/4.0/

(c) (i) Open Access

\section{Abstract}

The study was intended to highlight functional outcome and survival advantage when High Dose Rate (HDR) interstitial implant was used for anterior $2 / 3^{\text {rd }}$ tongue, either as a primary or as boost depending upon stage of disease. Materials and Methods: Fifty-one patients with squamous cell carcinoma of anterior $2 / 3^{\text {rd }}$ tongue received interstitial brachytherapy either as primary or as boost with Iridium 192 remote after loading high dose rate (Microselectron or Gamma MediX) machines from November 2008 to September 2013. Age group ranged from 32 to 73 years, mean 52.1. Of these 51,37 were males and 14 were females. 8 patients belonged to Stage $I, 18$ from Stage II and 28 patients were Stage III. Stage I patients received primary brachytherapy alone of dose $38.50 \mathrm{~Gy}$ to $40 \mathrm{~Gy}$ and fraction dose ranged from $250 \mathrm{cGy}$ to $350 \mathrm{cGy}$. Stage II and Stage III patients received external beam radiation of dose $44 \mathrm{~Gy} / 200 \mathrm{cGy}$ per fraction for 22 fractions followed by spinal cord sparing for $6 \mathrm{~Gy} / 200 \mathrm{cGy}$ per fraction for 3 fractions. Brachytherapy boost of dose 21 Gy was delivered after external beam radiation. Stage III patients received concurrent chemotherapy with Injection Cisplatin along with external beam radiotherapy $44 \mathrm{~Gy} / 200 \mathrm{cGy}$ per fraction for 22 fractions followed by spinal cord sparing for 6 Gy/200cGy per fraction for 3 fractions. Brachytherapy boost of dose 21 Gy was delivered after external beam radiation. 55\% of patients were habituated to tobacco and alcohol in one form or the other or both. Surprisingly $45 \%$ of patients were nonsmokers and non-alcoholic. Results: Follow-up period ranged from eight months to sixty months. 42 patients had complete response. 9 patients had residual disease. 2 patients died due to non-cancerous cause though they had excellent local control, one with pulmonary tuberculosis and the other with massive Myocardial Infarction. 2 patients died due to disease progression. 
Overall complete response rate was $\mathbf{8 2 . 3 5 \%}$. Those patients who had good coverage index and conformal index had good response compared to those patients with lesser these values. Conclusion: It is surprising to observe from the study that oral cavity cancers are not uncommon in nonsmokers and non-alcoholics. Overall complete response of $82 \%$ is comparable to any other study quoted in literature. Surgery offers same cure rate but at the rate of organ loss and functional impairment. Organ preservation with good functional outcome is possible in radiotherapy unlike surgery. This study proves brachytherapy can be considered as a surrogate to surgery in early stage tongue cancers with good functional outcome and with lesser morbidity.

\section{Keywords}

Tongue Cancer, High Dose Rate Interstitial Brachytherapy, Organ Preservation

\section{Introduction}

Despite oral cavity cancer remains more prevalent and easily accessible site, treatment and survival still remains enigma. It often eludes the treating surgeons and physicians despite technological strides and safe surgical procedure. No breakthrough occurred in survival rate for oral cancers in recent past particularly in less developed countries [1]-[3]. Major reasons may be $60 \%$ to $80 \%$ of them report at advanced stage compared to $40 \%$ in developed countries [3] [4]. About $90 \%$ of oral cavity cancers are squamous cell carcinoma and nodal metastasis range from $15 \%$ to $75 \%$ depending on the size of the primary lesion [3]-[5]. Frequency of nodal metastasis always dictates prognosis and survival [6] [7]. 5-year survival rate can be as high as $72 \%$ to $90 \%$ for patients without lymph node metastasis but devolves to $50 \%$ with node positivity [8].

Recent Globocan 2012 statistics states that age standardized risk for oral cavity was 4\% and mortality rate was $1.2 \%$ for the world population, whereas in India 7.2 and 4.9 respectively for both sexes [9]. Contrary to school of thought about smoking, alcohol, spicy food considered as potential risk factors for oral cavity cancers, it is often observed in non-smokers and non-alcoholics as well. Predisposition to genetic instability has been hypothesized as a likely cause [10]. Human Papilloma Virus (HPV) 6 and 16 are also implicated as a probable causative factor. HPV 16 confers three fold risk of developing oral cavity cancers. Though HPV infections have been detected in $50 \%$ of oral cavity cancers but it is still elusive whether infection with virus is sufficient to develop oral cavity cancers [11]-[13].

Though surgery and radiotherapy offer same cure rate in early oral tongue lesions, surgery often results in organ loss with impairment of its function. Some patient may require adjuvant radiotherapy after surgery if postoperative histopathology shows resected margins positivity or if extra capsular spread is noted, there by further aggravating post-operative morbidity. Patients who have complete response with radiotherapy can retain their organ with reasonably good functional outcome. Patients with residual disease after radiotherapy can still be salvaged with surgery [14]-[16]. Studies have shown better local control in oral cavity cancers with high dose rate brachytherapy boost compared to external beam radiotherapy alone even in case of T3 and T4 stages [17]. Very few trials were done with concurrent chemo irradiation followed by brachytherapy boost in early stage head and neck cancers [17]. The purpose of the study was to establish the impact of brachytherapy either as primary treatment alone or as the boost in early tongue cancers in Indian patients and their tolerance to concurrent chemo irradiation and brachytherapy boost in stage III oral tongue lesions.

\section{Materials and Methods}

The study was carried out from November 2008 to September 2013 in Jawaharlal Institute of Postgraduate Medical Education \& Research (JIPMER) Hospital, Puducherry, India. About 51 patients with squamous cell carcinoma of tongue were recruited. Age group ranged from 32 to 73 years, Mean 52. Of these 37 were males and 14 females. Details of patient profiles are summarized in Table 1 and Table 2.

All the patients underwent complete staging workup, which include physical examination, Contrast Enhancing Computerized Tomography (CECT) Head and Neck, Chest X-Ray PA View, necessary blood investigations 
Table 1. Patients profile.

\begin{tabular}{|c|c|c|}
\hline Distribution & Number & Percent \\
\hline Number of Patients & 51 & \\
\hline Age Group (in Years ) & \multicolumn{2}{|c|}{ Range: 32 to 73 , Mean 52.1} \\
\hline Male & 37 & 72.5 \\
\hline Female & 14 & 27.45 \\
\hline \multicolumn{3}{|l|}{ Performance Status } \\
\hline ECOG 1 & 28 & 54.9 \\
\hline ECOG 2 & 23 & 45.1 \\
\hline \multicolumn{3}{|l|}{ Habits } \\
\hline Male Tobacco Chewing Alone & 1 & 1.96 \\
\hline Male Alcohol + Betel Nut Chewing + Tobacco Chewing & 1 & 1.96 \\
\hline Male - Smoking Alone & 7 & 13.7 \\
\hline Male - Alcohol Alone & 1 & 1.96 \\
\hline Male - Smoking + Alcohol & 7 & 13.7 \\
\hline Male - Smoking + Tobacco & 2 & 3.92 \\
\hline Male - None & 16 & 31.4 \\
\hline Male - Betel Nut Chewing + Smoking & 1 & 1.96 \\
\hline Male - Betel Nut Chewing + Alcohol & 1 & 1.96 \\
\hline Female - None & 7 & 13.7 \\
\hline Female - Betel Nut Alone & 4 & 7.8 \\
\hline Female - Tobacco Alone & 3 & 5.9 \\
\hline \multicolumn{3}{|c|}{ Growth Characteristics } \\
\hline Infiltrative Disease & 13 & 25.5 \\
\hline Proliferative Disease & 35 & 68.6 \\
\hline Both & 3 & 5.9 \\
\hline \multicolumn{3}{|l|}{ Disease Status } \\
\hline T1 Disease & 5 & 9.8 \\
\hline T2 Disease & 23 & 45.1 \\
\hline T3 Disease & 23 & 45.1 \\
\hline T2N1 Disease & 5 & 9.8 \\
\hline T3N1 Disease & 6 & 11.7 \\
\hline \multicolumn{3}{|l|}{ Outcome } \\
\hline Complete Response & 42 & 82.35 \\
\hline Residual Disease & 9 & 17.6 \\
\hline Expired Due to Cancer Progression & 2 & 3.9 \\
\hline Expired Due to Non-Cancerous Cause & 2 & 3.9 \\
\hline Expired (Total) & 4 & 7.8 \\
\hline
\end{tabular}


Table 2. Response details.

\begin{tabular}{ccc}
\hline TNM Stage & Number & Complete Response (\%) \\
\hline T1 Disease & 5 & 100 \\
T2 Disease & 23 & 82.6 \\
T3 Disease & 23 & 78.2 \\
T1N0 & 5 & 100 \\
T2N0 & 18 & 83.3 \\
T3N0 & 17 & 82.35 \\
T2N1 Disease & 5 & 80 \\
T3N1 Disease & 6 & 66.7 \\
Node alone N1 & 11 & 72.7 \\
Stage 1 & 5 & 100 \\
Stage II & 18 & 83.3 \\
Stage III & 28 & 78.6 \\
& 35 & 76.9 \\
Proliferative & Growth Pattern & 82.8 \\
Infiltrative & 13 & 100 \\
Both & 35 & \\
\hline & 3 & \\
\hline
\end{tabular}

and anesthesia fitness. All patients were staged based on AJCC $-7^{\text {th }}$ Edition staging and all patients were treated based on their stage.

\subsection{Treatment Details}

$\mathrm{T} 1$ disease patients were considered for primary brachytherapy alone; patients with $\mathrm{T} 2$ and above stages irrespective of nodal involvement were considered for External Beam Radiation (EBRT) followed by brachytherapy boost with Iridium 192 high dose rate brachytherapy.

Five patients with $\mathrm{T} 1$ disease received brachytherapy alone. 46 patients received EBRT followed by brachytherapy. EBRT was delivered in Clinac 600c with 6 MV photon energy. 2 dimensional conformal planning was done for all 46 patients. With thermoplastic immobilization, simulation was done in Varian conventional simulator. Bite block was used to depress the tongue. The opposing lateral beam with lower anterior neck field was planned with mono isocentre technique with asymmetric jaws for field matching between lateral and lower anterior neck field. This takes care of junctional hot/cold spot. EBRT was delivered at $2 \mathrm{~Gy}$ per fraction, 5 fractions per week up to $44 \mathrm{~Gy}$ followed by anteriorization of 2 lateral fields to spare the spinal cord for dose up to $6 \mathrm{~Gy}$. The mid line block was used to protect spinal cord in lower anterior neck field. Total dose to both opposing lateral and lower anterior neck field was $50 \mathrm{~Gy}$. All the involved nodes were boosted with brachytherapy for EQD2 dose of 70 Gy.

\subsection{HDR Interstitial Brachytherapy Procedure}

Under general anesthesia, the skin is pierced at the planned entry site and coursed along in the tumor volume, exiting at the marked skin site at the other end of the target volume. The trocar and hollow needles were inserted as guide tubes in and around the tumor each $1 \mathrm{~cm}$ apart in a single or multiple planes through which flexible after loading plastic catheters secured with buttons on one side were threaded followed by the removal of trocar and needles. The (nylon) PLASTIC tubes were then secured by buttons on the exit side.

\subsection{Imaging, Planning and Implementation in Brachytherapy}

On the second day after implantation, the patients underwent CT scan of the involved region with a slice thick- 
ness of $1 \mathrm{~mm}$. Either Gamma MediX plus (Varian Medical Systems, Palo Alto, CA) or Microselectron HDRV3 (Nucletron, BV) using single sealed Iridium 192 radioactive source was used as the remote after-loading HDR brachytherapy treatment units shown in Figure 1 and Figure 2. Brachy Vision (Varian Medical Systems, Palo Alto, CA) or Oncentra Master Plan (Nucletron, BV) were used for treatment planning. Using CT Somatom spirit (Siemens) CT images were acquired and used for planning. The CT images were transferred to the treatment planning system. The target volume was delineated in the planning system and 3D treatment plan was made.

The applicator reconstruction was done and at the tip of all the applicators a reference point was inserted. The source dwell positions and step size were identified and accordingly the fine tuning of dose optimization was performed based on CTV by changing the dwell time and weight-age for individual dwell positions. In most cases, dwell time was changed to reduce the hot spot or to remove the cold spot. Graphical optimization was never used. It was ensured that at least $90 \%$ of the CTV receives the prescribed dose. The dose distribution was

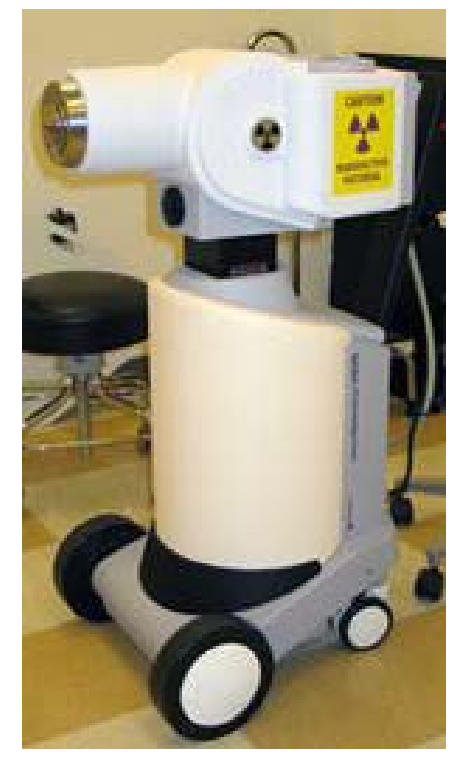

Figure 1. Microselectron HDRV3 (Nucletron).

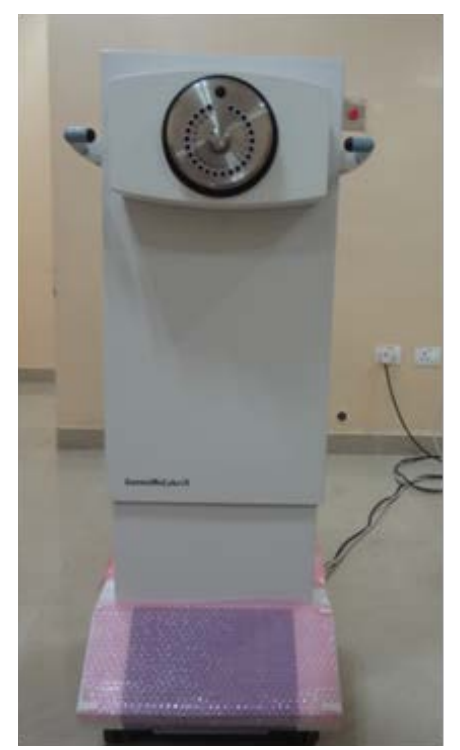

Figure 2. Gamma MediX plus machine (Varian medical systems). 
generated by TPS using the AAPM TG-43 dose formalism. Treatment was delivered using the HDR remote after-loading system. The dose prescribed was either $2.5 \mathrm{~Gy}$ or $3.5 \mathrm{~Gy}$ per fraction twice a day with an interval of 6 to 7 hours between the two. Using the cumulative Dose Volume Histogram (DVH) the dosimetric parameters were studied. 5 patients received primary brachytherapy alone. Of these 2 patients received $2.5 \mathrm{~Gy}$ per fraction, 2 fractions per day at 6 hours apart for 16 fractions. Total dose delivered was 40 Gy; remaining 3 patients received HDR brachytherapy 3.5 Gy per fraction, 2 fractions per day at 6 hours apart for 11 fractions. Total dose delivered was 3850 cGy. 46 patients received Iridium 192 HDR brachytherapy at 3.5 Gy per fraction, 2 fractions per day at 6 hours apart for 6 fractions after completing EBRT. Most of the patients received brachytherapy boost in 2 weeks. 4 patients received brachytherapy boost in $3^{\text {rd }}$ week, due to delay in healing grade 3 mucosities.

\subsection{Chemotherapy}

All the Stage III patients i.e., 28 patients received chemotherapy concurrently with EBRT. Injection Cisplatin 70 $\mathrm{mg} / \mathrm{m}^{2}$ was given in 3 divided doses concurrently every 3 weeks with EBRT. All the patients were analyzed for local control by physical examination and toxicities by RTOG morbidity scoring criteria.

\subsection{Follow-Up}

All patients were followed up every 2 months in first year, every 3 months in second year and every 4 months thereafter. Follow-up period ranged from eight months to sixty months.

\section{Statistical Analysis}

Baseline characteristics and distribution of patients according to treatment received were presented as frequencies and percentages. Dose parameters were expressed as mean \pm standard deviation. Pearson's chi square test and Fisher's exact test were used in subgroup analysis for treatment outcome. Binary logistic regression analysis and Spearman's correlation test were used for analysis of dose parameters and toxicities. All statistical tests were carried out at $5 \%$ level of significance and a P-value of $<0.05$ was considered statistically significant. SPSS software version 20 was used for statistical analysis.

\section{Ethical Considerations}

Informed consent in vernacular language was obtained from all participants after proper explanation of the treatment options. Ethical clearance from competent authority was obtained vide number [No. SEC/2011/4/101].

\section{Results}

From November 2008 to September 2013, 51 patients with early tongue lesions with squamous cell carcinoma treated with HDR Iridium192 brachytherapy either as primary or boost were evaluated for the response and toxicity. Table 3 summaries the response and influence of habits on tumor control, type of growth on tumor control, performance status on tumor control and their statistical powers were analyzed. Figure 3 shows pre-treatment gross disease and Figure 4 shows post-treatment complete response during follow-up period.

\subsection{Local Control}

Of the 51 patients 4 patients died. Two patients died of non-cancerous cause. Both of them had good local control. One patient had sudden myocardial infarction and died recently. Other patient developed sputum positive pulmonary tuberculosis after three years of post-radiotherapy period. He had excellent local control with minimal toxicity. He developed massive hemoptysis and died immediately before any intervention could be tried. 9 patients had residual disease. All the patients were sent to surgical oncology department for salvage surgery. Seven patients had good salvage surgery but two patients progressed after surgery and died within 3 months of post-operative period.

\subsection{Toxicity Profile}

All the patients completed treatment. None of the patients dropped out from the study. Mucositis was the most 
Table 3. (a) Comparison of treatment outcome in relation to gender; (b) Comparison of treatment outcome in relation to betel nut chewing; (c) Comparison of treatment outcome in relation to smoking; (d) Comparison of treatment outcome in relation to alcohol consumption; (e) Comparison of treatment outcome in relation to tobacco chewing; (f) Comparison of treatment outcome in relation to ECOG; (g) Comparison of treatment outcome in relation to ulcerative growth pattern; (h) Comparison of treatment outcome in relation to T-stage; (i) Comparison of treatment outcome in relation to stage; (J) Comparison of treatment outcome in relation to nodal-stage.

(a)

\begin{tabular}{|c|c|c|c|c|c|c|}
\hline \multirow{2}{*}{ Outcome } & \multicolumn{2}{|c|}{ Male } & \multicolumn{2}{|c|}{ Females } & \multirow{2}{*}{ Total } & \multirow{2}{*}{$P$ value } \\
\hline & $\mathrm{N}$ & $\%$ & $\mathrm{~N}$ & $\%$ & & \\
\hline Complete response & 30 & 81.081081 & 12 & 85.714286 & 42 & \\
\hline Residual disease & 7 & 18.918919 & 2 & 14.285714 & 9 & $<0.05$ \\
\hline \multirow[t]{2}{*}{ Total } & 37 & 100 & 14 & 100 & 51 & \\
\hline & \multicolumn{4}{|c|}{ Fishers-Exact-Test } & & 1 \\
\hline
\end{tabular}

(b)

\begin{tabular}{|c|c|c|c|c|c|c|}
\hline \multirow{2}{*}{ Outcome } & \multicolumn{2}{|c|}{ No betel nut chewing } & \multicolumn{2}{|c|}{ Betel nut chewing } & \multirow{2}{*}{ Total } & \multirow{2}{*}{$P$ value } \\
\hline & $\mathrm{N}$ & $\%$ & $\mathrm{~N}$ & $\%$ & & \\
\hline Complete response & 36 & 81.81818 & 6 & 85.71429 & 42 & \\
\hline Residual disease & 8 & 18.18182 & 1 & 14.28571 & 9 & $>0.05$ \\
\hline \multirow[t]{2}{*}{ Total } & 44 & 100 & 7 & 100 & 51 & \\
\hline & \multicolumn{4}{|c|}{ Fishers-Exact-Test (Chi square) } & & 1 \\
\hline
\end{tabular}

(c)

\begin{tabular}{|c|c|c|c|c|c|c|}
\hline \multirow{2}{*}{ Outcome } & \multicolumn{2}{|c|}{ No smoking } & \multicolumn{2}{|c|}{ Smoking } & \multirow{2}{*}{ Total } & \multirow{2}{*}{$P$ value } \\
\hline & $\mathrm{N}$ & $\%$ & $\mathrm{~N}$ & $\%$ & & \\
\hline Complete response & 27 & 79.41176 & 15 & 88.23529 & 42 & \\
\hline Residual disease & 7 & 20.58824 & 2 & 11.76471 & 9 & $>0.05$ \\
\hline \multirow[t]{2}{*}{ Total } & 34 & 100 & 17 & 100 & 51 & \\
\hline & \multicolumn{4}{|c|}{ Fishers-Exact-Test (Chi square) } & & 0.7 \\
\hline
\end{tabular}

(d)

\begin{tabular}{|c|c|c|c|c|c|c|}
\hline \multirow{2}{*}{ Outcome } & \multicolumn{2}{|c|}{ Non-Alcoholic } & \multicolumn{2}{|c|}{ Alcoholic } & \multirow{2}{*}{ Total } & \multirow{2}{*}{$\mathrm{P}$ value } \\
\hline & $\mathrm{N}$ & $\%$ & $\mathrm{~N}$ & $\%$ & & \\
\hline Complete response & 34 & 82.92683 & 8 & 80 & 42 & \\
\hline Residual disease & 7 & 17.07317 & 2 & 20 & 9 & $>0.05$ \\
\hline \multirow[t]{2}{*}{ Total } & 41 & 100 & 10 & 100 & 51 & \\
\hline & \multicolumn{4}{|c|}{ Fishers-Exact-Test (Chi square) } & & 1 \\
\hline
\end{tabular}

(e)

\begin{tabular}{|c|c|c|c|c|c|c|}
\hline \multirow{2}{*}{ Outcome } & \multicolumn{2}{|c|}{ No tobacco chewing } & \multicolumn{2}{|c|}{ Tobacco chewing } & \multirow{2}{*}{ Total } & \multirow{2}{*}{$P$ value } \\
\hline & $\mathrm{N}$ & $\%$ & $\mathrm{~N}$ & $\%$ & & \\
\hline Complete response & 37 & 84.09091 & 5 & 71.42857 & 42 & \\
\hline Residual disease & 7 & 15.90909 & 2 & 28.57143 & 9 & $>0.05$ \\
\hline \multirow[t]{2}{*}{ Total } & 44 & 100 & 7 & 100 & 51 & \\
\hline & \multicolumn{4}{|c|}{ Fishers-Exact-Test (Chi square) } & & 0.6 \\
\hline
\end{tabular}


(f)

\begin{tabular}{|c|c|c|c|c|c|c|}
\hline \multirow{2}{*}{ Outcome } & \multicolumn{2}{|c|}{ ECOG 1} & \multicolumn{2}{|c|}{ ECOG 2} & \multirow{2}{*}{ Total } & \multirow{2}{*}{$\mathrm{P}$ value } \\
\hline & $\mathrm{N}$ & $\%$ & $\mathrm{~N}$ & $\%$ & & \\
\hline Complete response & 24 & 85.71429 & 18 & 78.26087 & 42 & \\
\hline Residual disease & 4 & 14.28571 & 5 & 21.73913 & 9 & $>0.05$ \\
\hline Total & 28 & 100 & 23 & 100 & 51 & \\
\hline
\end{tabular}

Fishers-Exact-Test (Chi square)

(g)

\begin{tabular}{|c|c|c|c|c|c|c|c|c|}
\hline \multirow{2}{*}{ Outcome } & \multicolumn{2}{|c|}{ Proliferative } & \multicolumn{2}{|c|}{ Infiltrative } & \multicolumn{2}{|c|}{ both } & \multirow{2}{*}{ Total } & \multirow{2}{*}{$P$ value } \\
\hline & $\mathrm{N}$ & $\%$ & $\mathrm{~N}$ & $\%$ & $\mathrm{~N}$ & $\%$ & & \\
\hline Complete response & 29 & 82.8 & 10 & 76.9 & 3.0 & 100 & 42 & \\
\hline Residual disease & 6 & 17.14 & 3 & 23.07 & 0.0 & 0 & 9 & 0.6 \\
\hline \multirow[t]{2}{*}{ Total } & 35 & 100 & 13 & 100 & 3.0 & 100 & 51 & \\
\hline & \multicolumn{4}{|c|}{ Pearson's Chi square } & & & & 0.91 \\
\hline
\end{tabular}

(h)

\begin{tabular}{|c|c|c|c|c|c|c|c|c|}
\hline \multirow{2}{*}{ Outcome } & \multicolumn{2}{|c|}{$\mathrm{T} 1$} & \multicolumn{2}{|c|}{$\mathrm{T} 2$} & \multicolumn{2}{|c|}{ T3 } & \multirow{2}{*}{ Total } & \multirow{2}{*}{$P$ value } \\
\hline & $\mathrm{N}$ & $\%$ & $\mathrm{~N}$ & $\%$ & $\mathrm{~N}$ & $\%$ & & \\
\hline Complete response & 5 & 100 & 19 & 82.61 & 18 & 78.26 & 42 & \\
\hline Residual disease & 0 & 0 & 4 & 17.39 & 5 & 21.74 & 9 & 0.5 \\
\hline Total & 5 & 100 & 23 & 100 & 23 & 100 & 51 & \\
\hline \multicolumn{8}{|c|}{ Pearson's Chi square } & 1.3 \\
\hline
\end{tabular}

(i)

\begin{tabular}{|c|c|c|c|c|c|c|c|c|}
\hline \multirow{2}{*}{ Outcome } & \multicolumn{2}{|c|}{ Stage I } & \multicolumn{2}{|c|}{ Stage II } & \multicolumn{2}{|c|}{ Stage III } & \multirow{2}{*}{ Total } & \multirow{2}{*}{$\mathrm{P}$ value } \\
\hline & $\mathrm{N}$ & $\%$ & $\mathrm{~N}$ & $\%$ & $\mathrm{~N}$ & $\%$ & & \\
\hline Complete response & 5 & 100 & 15 & 83.33 & 22 & 78.57 & 42 & \\
\hline Residual disease & 0 & 0 & 3 & 16.67 & 6 & 21.42 & 9 & 0.5 \\
\hline \multirow[t]{2}{*}{ Total } & 5 & 100 & 18 & 100 & 28 & 100 & 51 & \\
\hline & \multicolumn{4}{|c|}{ Pearson's Chi square } & & & & 1.5 \\
\hline
\end{tabular}

(j)

\begin{tabular}{|c|c|c|c|c|c|c|}
\hline \multirow{2}{*}{ Outcome } & \multicolumn{2}{|c|}{ No } & \multicolumn{2}{|c|}{ N1 } & \multirow{2}{*}{ Total } & \multirow{2}{*}{$\mathrm{P}$ value } \\
\hline & $\mathrm{N}$ & $\%$ & $\mathrm{~N}$ & $\%$ & & \\
\hline Complete response & 39 & 97.5 & 3 & 27.27 & 42 & \\
\hline Residual disease & 1 & 2.5 & 8 & 72.72 & 9 & $<0.05$ \\
\hline Total & 40 & 100 & 11 & 100 & 51 & \\
\hline
\end{tabular}




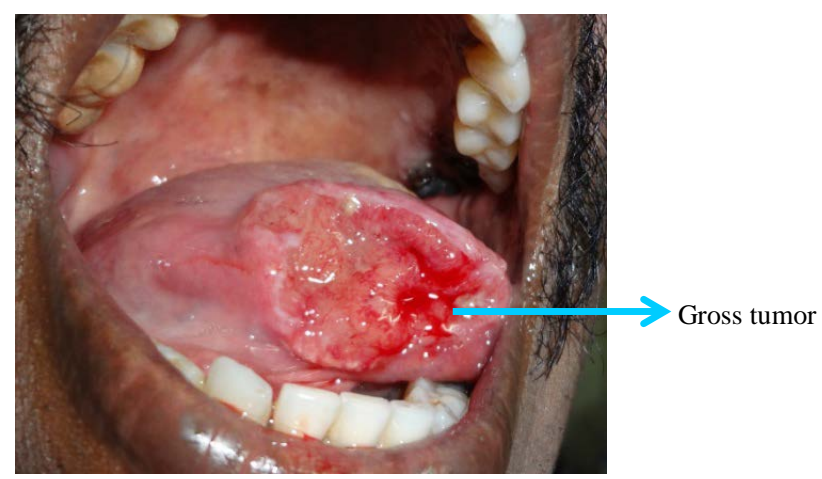

Figure 3. Pre-treatment gross tumor seen in right anterior $2 / 3^{\text {rd }}$ tongue carcinoma.

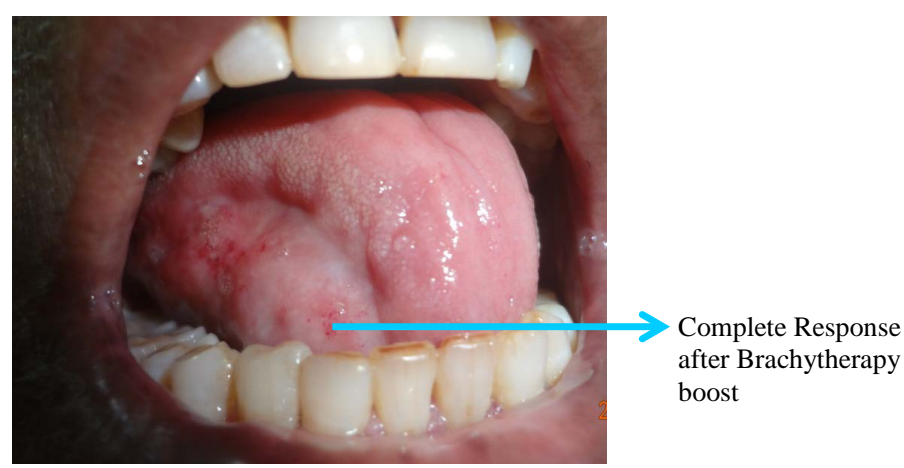

Figure 4. Complete response seen in right anterior $2 / 3^{\text {rd }}$ tongue carcinoma after completion of treatment on follow up.

common side effect. 14 patients had Grade III mucosities, more common when Injection Cisplatin was added with EBRT. 3 patients had Grade III skin reaction. Most of the other toxicities were manageable conservatively. Toxicity profiles are summarized in Table 4 and Table 5.

Three patients had osteoradionecrosis confirmed by CT scan, 5 patients developed soft tissue necrosis particularly when higher dose per fraction was used. 3 patients developed bleeding at the time of catheter removal.

\section{Discussion}

Though early tongue cancers are usually treated with wide local excision, but at the cost of portion of organ loss with some amount of functional impairment. However, radiotherapy has the advantage of preserving normal anatomy of the organ with good functional outcome [18] [19]. The advantages of brachytherapy are high localized dose with rapid dose fall off and short overall treatment duration [1] [2]. Sresty et al., reported that the interstitial brachytherapy treatment confers more dose homogeneity when compared with Intensity Modulated Radiation Therapy (IMRT) and lesser dose to critical structures as well as planning time was much less for most cases. He concluded that interstitial brachytherapy is an ideal option for high dose delivery exclusively to the primary tumor volume, while limiting the risk of severe xerostomia or trismus [20].

From the study, it was evident that there was no correlation between types of growth or habits influencing the treatment outcome. However, from the study we noticed about $45 \%$ of the patients were non-smokers and nonalcoholic. This entails to search for etiological agents other than smoking and alcohol. Probably HPV infections or genetic instability could be the offender in these patients [10] [12] [13].

Size of the primary lesion and nodal involvement definitely had an impact on the local control and survival. Smaller lesion patients had better local control and better survival compared larger lesions with nodal involvement as evident from statistical analysis [8] [21].

Most of the patients tolerated radiotherapy. Most common complaints patients reported were burning sensation over the dorsum of tongue. Zinc containing multivitamins definitely improved the problem. Loss of taste 
Table 4. Distribution of hemorrhage/osteoradionecrosis/soft tissue necrosis in the study group on follow up.

\begin{tabular}{cccc}
\hline Toxicity & & N & $\%$ \\
\hline \multirow{2}{*}{ Osteoradionecrosis } & NO & 48 & 94.11 \\
& YES & 3 & 5.88 \\
Soft tissue necrosis & NO & 46 & 90.19 \\
& YES & 5 & 9.8 \\
Haemorrhage & NO & 48 & 94.11 \\
& YES & 3 & 5.88 \\
\hline
\end{tabular}

Table 5. Toxicities observed during EBRT/CCRT and on follow up.

\begin{tabular}{|c|c|c|c|}
\hline Toxicities & & $\mathrm{N}$ & $\%$ \\
\hline \multirow{4}{*}{ Acute skin reaction } & G0 & 5 & 9.8 \\
\hline & G & 34 & 66.67 \\
\hline & G2 & 9 & 17.64 \\
\hline & G3 & 3 & 5.9 \\
\hline \multirow{4}{*}{ Acute mucositis } & G0 & 5 & 9.8 \\
\hline & G1 & 10 & 19.6 \\
\hline & G2 & 22 & 43.13 \\
\hline & G3 & 14 & 27.45 \\
\hline \multirow{3}{*}{ Acute dysphagia } & G0 & 6 & 11.76 \\
\hline & G1 & 38 & 74.50 \\
\hline & G2 & 7 & 13.72 \\
\hline \multirow{2}{*}{ Candidiasis } & $\mathrm{NO}$ & 24 & 47.05 \\
\hline & YES & 27 & 52.94 \\
\hline \multirow{3}{*}{ Xerostomia } & G0 & 5 & 9.8 \\
\hline & G1 & 14 & 27.45 \\
\hline & G2 & 32 & 62.74 \\
\hline \multirow{2}{*}{ Acute nausea } & $\mathrm{NO}$ & 34 & 66.67 \\
\hline & YES & 17 & 33.33 \\
\hline \multirow{3}{*}{ Acute vomiting } & G0 & 38 & 74.50 \\
\hline & G1 & 8 & 15.69 \\
\hline & G2 & 5 & 9.8 \\
\hline \multirow{2}{*}{ Neutropenia_G2 } & NO & 45 & 88.24 \\
\hline & YES & 6 & 11.76 \\
\hline
\end{tabular}

sensation was noticed by some patients but returned to normal after 6 months. Xerostomia was evident in some patient. They were encouraged to take plenty of liquid diet and some patients required artificial saliva [22].

Soft tissue necrosis was noticed in 5 patients, particularly when 3.5 Gy per fraction dose was used. But all the patients were managed conservatively. Only one patient required surgical invention [23].

The clinical target volume covered by $100 \%$ of isodose and the total mean dose received by clinical target volume was shown to have significant correlation with soft tissue necrosis [24].

Osteonecrosis was evident in 3 patients, confirmed by CT scan. 2 patients were managed conservatively with 
antibiotics and it got stabilized. They are on follow up till now. But one patient progressed after antibiotics; he was referred to surgical oncology for surgery. Dose of 1 сc, 2 сc, 5 сс, 10 сс of mandible and the volume of mandible receiving $100 \%, 150 \%$, and $200 \%$ of doses were greater for patients with osteonecrosis than without osteonecrosis [25].

Three patients had bleeding at the time of catheter removal. Compression with sterile dry gauze for about 10 to 15 minutes was required. Ice cubes in sealed container placed over the bleeding site controlled bleeding faster. No surgical intervention was required for any these patients.

From time immemorial brachytherapy has been fascinating technique for the radiation oncologists. Brachytherapy has been indispensable part in control of local disease and long term survival. It is proved beyond doubt in gynecological tumors. But its role in head and cancer is yet to be defined.

The majority of the published results were based on low-dose-rate and manual after loading techniques. However, recent HDR remote after loading device with treatment planning with 3D imaging available, dose to tumor tissue with much sparring of nearby organ at risk to a desired level is possible. Though the use of 3D image-based approach for GTV and CTV assessment and optimization is the need of the hour, but dose recommendations and common language to describe the concepts/defined terms are yet to be ascertained in brachytherapy of head and neck tumors.

In this study, various indices like Coverage Index (CI), Dose Homogeneity Index (DHI), Dose-Non-Uniformity Ratio (DNR), Conformal Index (COIN) and External Volume Index (EVI) used were calculated and compared with the reference dose. These indices rely on 3D image based approach and volume based optimization. In this study, Clinical Target Volumes (CTV) were contoured and dose was prescribed to the isodose covering the target.

According to American brachytherapy society recommendations Coverage Index of 100\%, Dose Homogeneity Index of more than 0.75 and External Volume Index of zero $(E V I=0)$ should be achieved with more than 90\% of dose delivered to $>90 \%$ target volume. Baltas et al., stated that conformal index should be one (1) in order to achieve better quality of tumor irradiation and normal tissue sparing by interstitial brachytherapy [26]-[28].

In this study group, the mean Coverage Index was 0.8 (ideal 1 but can extend from 0.8 to 1.2) Dose Homogeneity Index 0.7 (ideal 0.75), Dose-Non-uniformity Ratio 0.3 (ideal 0.1), Conformal Index 0.74 (ideal 1) and External Volume Index of 0.05 (ideal 0.05) and all the parameters were well within recommended value but for Conformal Index.

We had clinical correlation only for Coverage Index and Conformal Index, other indices did not have any clinical correlations. Various indices are summarized in Table 6.

\begin{tabular}{cccccc} 
Table 6. Various indices. & \multicolumn{3}{c}{ R } \\
\hline \multirow{2}{*}{ Indices } & CR & & Mean & SD \\
\cline { 2 - 5 } & Mean & SD & 0.703711 & 0.056908 \\
CI & 0.8004366 & 0.062127 & 0.710205 & 0.118326 \\
DHI & 0.691138 & 0.123663 & 0.261967 & 0.133971 \\
DNR & 0.324139 & 0.118688 & 0.079544 & 0.089651 \\
EVI & 0.047848 & 0.031914 & 0.674625 & 0.11647 \\
COIN & 0.761807 & 0.084337 & 0 &
\end{tabular}

Abbreviations: CR, complete response; R, residual disease; CI, coverage index; DHI, dose homogeneity index; COIN, conformal index; DNR, dose non uniformity ratio; EVI, external volume index; SD, standard deviation.

- Spearman's correlation test-CI, DHI, DNR, COIN CI $(\mathrm{P}<0.0002)$ and COIN $(\mathrm{P}<0.037)$ are significantly correlated.

- Logistic regression analysis-CI, DHI, DNR, COIN Significant effect of $(\mathrm{P}=0.024)$ Coverage index on complete response.

- Spearman's correlation test Total dose, V200\%, V150\%, V100\%, V90\%

Total dose $(\mathrm{P}<0.0001)$ and V200\% $(\mathrm{P}<0.02)$ are significantly correlated.

- Logistic regression analysis

Total dose, V200\%, V150\%, V100\%, V90\%, no significant effect on complete response. 
Those patients with ideal Coverage Index and Conformal Index had complete response compared those patients who had residual disease. In residual disease patients, Coverage Index and Conformal Index were lesser than the recommended value (statistically significant). It is evident from the study that good brachytherapy technique definitely plays a role in obtaining complete response.

\section{Conclusion}

Though surgery is preferred over radiotherapy in early tongue lesions, still brachytherapy with or without external beam radiation can be a surrogate to surgery in early oral cavity cancers due to organ preservation with good functional outcome. Salvage surgery is possible for radiotherapy failure patients. Good brachytherapy techniques and meticulous planning can definitely minimize toxicity with better tumor control resulting in better survival rate. Optimization can never replace good brachytherapy technique. It is desirable to implant more flexible tubes equidistant from other than restricting the number of catheters. This gives more room for uniform dose delivery and better Homogeneity Index and Conformal Index, which testifies the end point of all interstitial implants.

\section{References}

[1] Ballonoff, A. and Chen, C. (2006) Current Radiation Therapy Management Issues in Oral Cavity Cancer. Otolaryngologic Clinics of North America, 39, 365-380.

[2] Taktak, A.F.G. and Fisher, A.C. (2007) Outcome Predictions in Cancer. Elsevier, Amsterdam, 1-14.

[3] Coelho, K.R. (2012) Challenges of the Oral Cancer Burden in India. Journal of Cancer Epidemiology, 2012, Article ID: 701932.

[4] Khan, Z.U. (2012) An Overview of Oral Cancer in Indian Sub-Continent and Recommendation to Decrease Its Incidence. Webmed Central Cancer, 3, Article ID: WMC003626.

[5] Jemal, A., Bray, F., Center, M.M., Ferlay, J. and Ward, E. (2011) Global Cancer Statistics. A Cancer Journal for Clinicians, 61, 69-90.

[6] Hiratsuka, H., Miyakawa, A., Nakamori, K., et al. (1997) Multivariate Analysis of Occult Lymph Node as a Prognostic Indicator for Patients with Squamous Cell Carcinoma for the Oral Cavity. Cancer, 80, 351-356.

[7] Shear, M. and Hawkins, D.M. (1976) The Prediction of Lymph Node Metastases from Oral Squamous Cell Carcinoma. Cancer, 37, 1901-1907. http://dx.doi.org/10.1002/1097-0142(197604)37:4<1901::AID-CNCR2820370440>3.0.CO;2-U

[8] Halperin, E.C., Brady, L.W., Perez, C.A. and Wazer, D.E. (2008) Perez and Brady's Principles and Practice of Radiation Oncology. 5th Edition, Lippincott Williams \& Wilkins (LWW), Philadelphia, 891-912.

[9] Globocan (2012) Estimated Cancer Incidence Mortality and Prevalence Worldwide in 2012. International Agency for Research on Cancer, Lyon. http://globocan.iarc.fr

[10] Llewellyn, C.D., Johnson, N.W. and Warnakulasuriya, K.A.A.S. (2001) Risk Factors for Squamous Cell Carcinoma of Oral Cavity in Foms People; a Comprehensive Literature Review. Oral Oncology, 37, 401-418. http://dx.doi.org/10.1016/S1368-8375(00)00135-4

[11] Miller, C.S. and Johnstone, B.M. (2001) Human Papillomavirus as a Risk Factor for Oral Squamous Cell Carcinoma, a Meta-Analysis 1982-1997. Oral Surgery, Oral Medicine, Oral Pathology, Oral Radiology, and Endodontology, 91, 622-635. http://dx.doi.org/10.1067/moe.2001.115392

[12] Myers, E. (2003) Cancer of the Head and Neck. Saunders, Philadelphia.

[13] Maden, C., Beckmann, A.M., et al. (1992) Human Papillomavirus, Herpes Simplex Virus and the Risk of Oral Cancer in Men. American Journal of Epidemiology, 135, 1093-1102.

[14] O’ Brien, C.J., Lahr, C.J., Soong, S.J., Gandour, M.J., et al. (1986) Surgical Treatment of Early Stage Carcinoma of the Oral Tongue-Would Adjuvant Treatment Be Beneficial. Head and Neck Surgery, 8, 401-408. http://dx.doi.org/10.1002/hed.2890080603

[15] Kolokythas, A. (2010) Long Term Surgical Complications in the Oral Cancer Patient: A Comprehensive Review—Part I. J Oral Maxillofac Res., 1, e1. http://dx.doi.org/10.5037/jomr.2010.1301

[16] Kolokythas, A. (2010) Long Term Surgical Complications in the Oral Cancer Patient: A Comprehensive Review—Part II. J Oral Maxillofac Res., 1, e2. http://dx.doi.org/10.5037/jomr.2010.1301

[17] Studer, G., Zwahlen, R.A., et al. (2007) IMRT in Oral Cavity Cancer. Radiation Oncology, 2, 16. http://dx.doi.org/10.1186/1748-717X-2-16 
[18] Matsui, Y. and Ohno, K. (2007) Factors Influencing Post-Operative Speech Function of Tongue Cancer Patients Following Reconstruction with Fasciocutaneous/Myocutaneous Flaps-A Multi Centre Study. International Journal of Oral and Maxillofacial Surgery, 36, 601-609. http://dx.doi.org/10.1016/j.ijom.2007.01.014

[19] Kellas-Sleczka, S., et al. (2010) Interstitial HDR Brachytherapy in Early Stage Mobile Tongue Caners in Young Patient-Gliwice Experience. Journal of Contemporary Brachytherapy, 2, 61-63.

[20] Sresty, N.V. and Ramanjappa, T. (2010) Acquisition of Equal or Better Planning Results with Interstitial Brachytherapy When Compared with Intensity Modulated Radiotherapy in Tongue Cancers. Brachytherapy, 9, 235-238. http://dx.doi.org/10.1016/j.brachy.2009.05.006

[21] Niladri, B. and Patra, J.G., et al. (2009) Outcome of High Dose Rate Interstitial Boost Brachytherapy Afterexternal Beam Radiation Therapy in Head and Neck Cancer. An Indian (Single Institutional) Learning Experience. Brachytherapy, 8, 248-254. http://dx.doi.org/10.1016/j.brachy.2008.12.006

[22] Emami, B. and Lyman, J. (1991) Tolerance of Normal Tissue to Therapeutic Irradiation. International Journal of Radiation Oncology*Biology*Physics, 21, 109-122.

[23] Devlin, P.M. (2007) Brachytherapy Applications and Techniques. Lippincott Williams \& Wilkins, Philladelphia, 63.

[24] Oota, S. and Shibuya, H. (2006) Brachytherapy of Stage II Mobile Tongue Carcinoma. Prediction of Local Control and QOL. Radiation Oncology, 1, 21. http://dx.doi.org/10.1186/1748-717X-1-21

[25] Fujita, M. and Hirokawa, Y. (1996) An Analysis of Mandibular Bone Complications in Radiotherapy for T1 and T2 Carcinoma of the oral Tongue. International Journal of Radiation Oncology*Biology*Physics, 34, 333-339.

[26] Mazeron, J.-J., Ardiet, J.-M., et al. (2009) GEC-ESTRO Recommendations for Brachytherapy for Head and Neck Squamous Cell Carcinomas. Radiotherapy and Oncology, 91, 150-156. http://dx.doi.org/10.1016/j.radonc.2009.01.005

[27] Feuvret, L. and Noel, G. (2006) Conformity Index; a Review. International Journal of Radiation Oncology*Biology*Physics, 64, 333-342. http://dx.doi.org/10.1016/j.ijrobp.2005.09.028

[28] Kehwar, T.S. and Akber, S.F. (2008) Qualitative Dosimetric and Radiobiological Evaluation of High Dose Rate Interstitial Brachytherapy Implants. International Journal of Medical Sciences, 5, 41-49. http://dx.doi.org/10.7150/ijms.5.41 
Scientific Research Publishing (SCIRP) is one of the largest Open Access journal publishers. It is currently publishing more than 200 open access, online, peer-reviewed journals covering a wide range of academic disciplines. SCIRP serves the worldwide academic communities and contributes to the progress and application of science with its publication.

Other selected journals from SCIRP are listed as below. Submit your manuscript to us via either submit@scirp.org or Online Submission Portal.
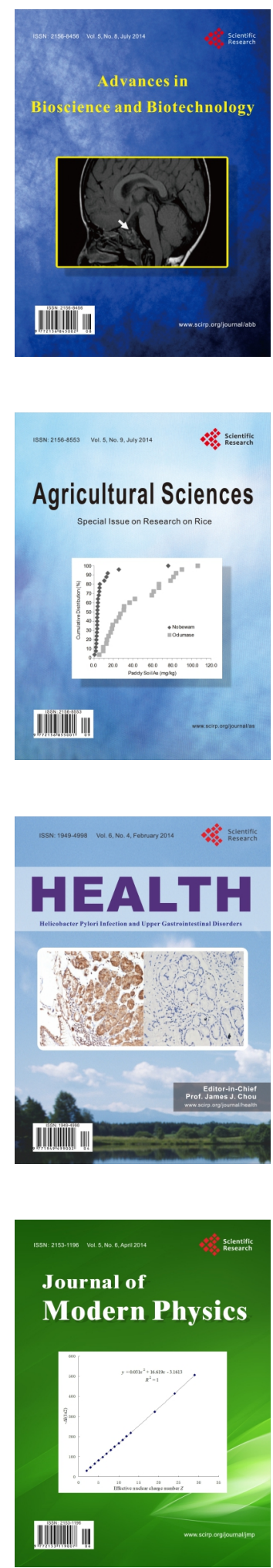
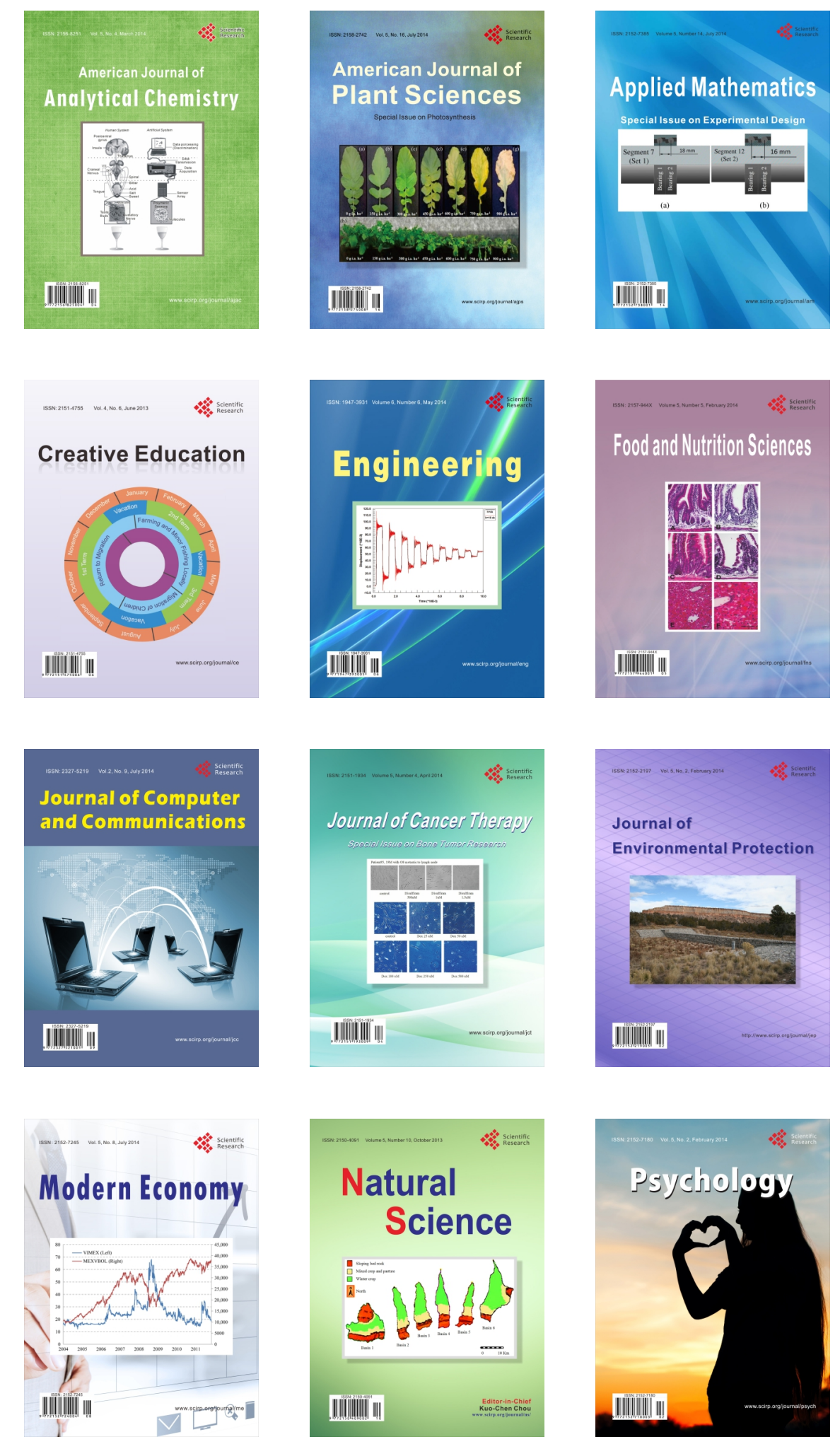